\title{
Skin morphology of the mutant hairless USP mouse
}

S.M.G. Massironi² M.R. Giacóia ${ }^{1}$, P.C. Maiorka ${ }^{1}$,

T.L. Kipnis ${ }^{3}$ and M.L.Z. Dagli ${ }^{1}$

\author{
Departamentos de ${ }^{1}$ Patologia, Faculdade de Medicina Veterinária e Zootecnia, and \\ ${ }^{2}$ Imunologia, Instituto de Ciências Biomédicas, Universidade de São Paulo, \\ São Paulo, SP, Brasil \\ ${ }^{3}$ Laboratório de Biologia do Reconhecer, Centro de Biotecnologia, \\ Universidade Estadual do Norte Fluminense, Campos dos Goytacazes, RJ, Brasil
}

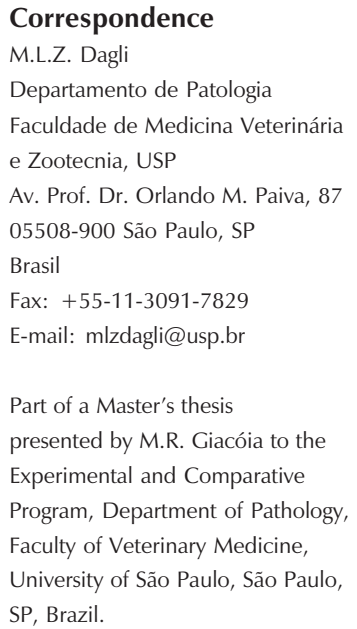

M.R. Giacóia was the recipient of a FAPESP fellowship (No. 95/1737-7).

\begin{abstract}
The morphology of the skin of the mutant hairless USP mouse was studied by histological, histochemical and immunohistochemical methods and compared to the skin of BALB/c mice. Representative sections of the dorsal skin from mice of both strains aged 18 days, and 1 , 3,6 , and 8 months were studied. Sections stained with hematoxylin and eosin showed cystic formations called utricles and dermal cysts in the dermis that increased in size and number during growth. Skin thickness increased significantly at 8 months. Sections stained with picrosirius and examined with polarized light, displayed different colors, suggesting different thicknesses of dermal collagen fibers (probably types I and III). Weigert, Verhoeff and resorcin-fuchsin stains revealed fibers of the elastic system. The PAS and Alcian blue methods revealed neutral and acid glycosaminoglycans in the skin ground substance of both mouse strains. Immunohistochemical staining for fibronectin and laminin did not show differences between the mutant and BALB/c mice. Mast cells stained by the Gomori method and macrophages positive for HAM 56 antibodies were observed in both mouse strains. Except for the presence of enlarged cysts in the hairless strain, no qualitative differences were found during development of the skin of BALB/c and the mutant hairless mice.
\end{abstract}

.................. Introduction

The hairless and rhino mutants are the most intensively studied models of hair cycle defects. Affected mice lose their hair progressively from the head to the tail at the end of the first hair cycle because the second hair cycle is defective (1). The rhino mutant presents severe lesions at the skin, which becomes progressively loose and redundant, forming folds, flaps and ridges (2).
Key words

- Mutant mice

- hrUSP mutants

- Hairless mice

- BALB/c mice

- Ethyl-nitrosourea

$\ldots \ldots \ldots \ldots \ldots \ldots$

Two of the authors (SMGM and TK) developed an ethyl-nitrosourea (ENU)-induced mutant phenotypically similar to the rhino mutant which was called hairless USP $\left(h r^{\text {USP }}\right)$. Differently from the hairless mice described earlier, this mutant does not show a defined pattern of hair loss. After the first hair cycle, hair is lost over the whole body at the same time and the loss progresses until the mice are fully naked (3). To determine if the $\mathrm{hr}^{\mathrm{USP}}$ and rhino mutants might be alleles 
of the same gene, heterozygous mice of both strains were mated. Fifty percent of $\mathrm{hr}^{\mathrm{USP}} /+$ and rhino/+ offspring showed the hairless phenotype, indicating that the two mutations do not complement each other in vivo, being alleles of a single gene.

The skin of hrUSP mice displays a thin epidermis formed by a stratified epithelium covering a dermis rich in cyst-like structures. These cysts are surrounded by scarce connective tissue and are apparently connected to sebaceous glands (3). In this report, we describe the kinetics of the development of the skin lesions in hrUSP mutant mice. Histological, histochemical and immunohistochemical methods, as well as morphometry, were applied, and the data were compared to those obtained for BALB/c mice.

\section{Material and Methods}

Animals

$\mathrm{BALB} / \mathrm{c}$ and $\mathrm{hr}$ USP mice were obtained from the isogenic mouse facility of the Department of Immunology, Institute of Biomedical Sciences, University of São Paulo, São Paulo, SP, Brazil. The recessive mutation hairless $\mathrm{hr}^{\mathrm{USP}}$ arose in an ENU mutagenesis program and has been maintained in a $\mathrm{BALB} / \mathrm{c}$ background. Its origin and main phenotype have already been described (3). Male or female hairless mice aged 18 days and 1, 3, 6, and 8 months were studied and $\mathrm{BALB} / \mathrm{c}$ mice of the same ages were used as

Table 1. Histochemical methods used to identify structures in the skin of hrUSP mutants and BALB/c mice.

\begin{tabular}{llc}
\hline Structure & Staining method & Reference \\
\hline Collagen fibers & Picrosirius polarization & 4 \\
Reticular fibers & Reticulin & 7 \\
Elastic fibers & Ferric hematoxylin of Verhoeff & 8 \\
Elastic fibers & Weigert resorcin-fucsin. with & 9 \\
(elauninic and oxytalanic) & oxidation by the oxone & 10 \\
Acid polysaccharides & Alcian blue & 11 \\
Neutral polysaccharides & Periodic-acid-schiff (PAS) & 12 \\
Mast cells granules & Gomori's aldehyde-fuchsin &
\end{tabular}

controls. During the experimental period, mice were kept in clean rooms provided with sanitary barriers. The temperature was kept at $21 \pm 2^{\circ} \mathrm{C}$, with light cycles of $12 \mathrm{~h}$. During the experimental period, mice received commercial food (Nuvital ${ }^{\circledR}$, Nuvilab, Curitiba, PR, Brazil) and water ad libitum.

\section{Skin samples}

Mice aged 18 days and $1,3,6$, or 8 months were euthanized by cervical dislocation, and their back region was shaved when necessary. A longitudinal fragment of 4 x 1.5 $\mathrm{cm}$ of the dorsal skin was obtained from each mouse and fixed in either Bouin's fixative or $95 \%$ ethanol for $24 \mathrm{~h}$. After routine processing, samples were embedded in paraffin and the $5-\mu \mathrm{m}$ sections were stained with hematoxylin and eosin (H\&E). Additional sections were attached to silanized slides for immunohistochemistry.

\section{Morphometry}

A Bioscan/Optimas (Bioscan Optimas, Bioscan Inc., Edmonds, WA, USA) image analysis system was used to quantify the skin thickness of hairless and BALB/c mice. The skin of 5 mutants and control BALB/c mice aged 18 days and $1,3,6$, or 8 months was sampled and at least 10 microscopic fields of each H\&E section were measured for each time. A 40X objective was used to measure the thickness of the epidermis, with lines perpendicular to the basal membrane drawn until the keratin layer. A 10X objective was used to measure dermis thickness, with lines drawn from the basal membrane towards the dermis muscle.

\section{Histochemical and immunohistochemical staining methods}

The histochemical methods used to identify the structures in the mouse skin are presented in Table 1. Skin fragments fixed in 95\% 
alcohol were used for immunostaining, thus avoiding the antigen retrieval which is necessary for immunostaining in formalin-fixed tissues. After dewaxing and hydration, sections were treated for 30 min with $15 \% \mathrm{H}_{2} \mathrm{O}_{2}$ in absolute methanol for $30 \mathrm{~min}$ to block endogenous peroxidase. Sections were washed and incubated overnight with the primary antibodies (Table 2) in a humid chamber at $4^{\circ} \mathrm{C}$, followed by incubation with a biotinylated secondary antibody and the streptavidin-biotin-peroxidase complex (Duet kit, Dako, Glostrup, Denmark). Peroxidase activity was then detected with a solution containing diaminobenzidine and hydrogen peroxide. Sections were counterstained with hematoxylin and mounted in synthetic resin.

\section{Statistical analysis}

Differences between means were tested by ANOVA, with the level of significance set at $\mathrm{P}<0.05$.

\section{Results}

\section{Gross observations}

At birth, hruSP hairless mice were indistinguishable from wild-type $\mathrm{BALB} / \mathrm{c}$ mice. However, from the 3 rd week of life on, hairless mice started to lose hair continuously, and became completely devoid of a hair coat by 45 days of age. However, they kept their vibrissae. In parallel with the hair loss, skin folding started to become evident. These folds covered the eyes, causing visual difficulties. Besides showing increased thickness, the skin of the $\mathrm{hr}^{\mathrm{USP}}$ hairless mouse became irregular and viscous, and white cysts could easily be seen all over the body. The nails grew continuously and became curved.

\section{Histopathology of the skin of the hr USP mutant}

The skin of BALB/c mice (Figure 1A), used as control, did not show any detectable change between the ages of 18 and 240 days. hr USP skin at 18 days of age (Figure 1B). A discrete invagination of the epidermis, moderate hyperkeratosis and small dermal cysts and utricles restricted to the upper portion of the skin close to the epidermis were observed. The dermal cysts and utricles were filled with lamellae of keratin, and some still showed the presence of hairs. Sebaceous glands were normally seen together with the hair follicles, dermal cysts and utricles. No other alteration could be seen in H\&E-stained slides.

hrUSP skin at 30 days of age (Figure 1C). The epidermis presented orthokeratotic keratosis. Dilated hair follicles were seen in the dermis, as well as larger utricles and dermal cysts when compared to 18 days of age. Dermal cysts were frequently seen in the superficial dermis and were frequently filled with keratin lamellae. Some atrophic hair follicles could be seen.

hr USP skin at 90 days of age (Figure 1D). The epidermal hyperkeratosis was more intense since utricles and the dermal cysts were more prominent and occupied most of the dermis, extending to the deep dermis (Figure 1D). Deeper dermal cysts showed less keratin. Functional hair follicles were not observed, but sebaceous glands were still seen around the hair follicles. The hypodermis was scant.

hrUSP skin at 180 days of age (Figure 1E). The epidermal hyperkeratosis was even more pronounced; utricles and dermal cysts were even more prominent and occupied most of the dermis, extending to the deep dermis. At

Table 2. Primary antibodies used for immunohistochemical staining of the skin of hrUSP mutants and BALB/c mice, and their dilutions.

\begin{tabular}{lll}
\hline Antibody & Source & Dilution \\
\hline Cytokeratins (AE1/AE3) & BioGenex ${ }^{\circledR}$, San Ramon, CA, USA & $1: 1000$ \\
Macrophages - HAM 56 & Dako ${ }^{\circledR}$, Carpinteria, CA, USA & $1: 50$ \\
Fibronectin & Dako $^{\circledR}$, Carpinteria, CA, USA & $1: 1000$ \\
Laminin & Dako $^{\circledR}$, Carpinteria, CA, USA & $1: 20$
\end{tabular}


Figure 1. Photomicrographs of skin from BALB/c (A) and hr USP mice at 18 days of age (B), 30 days (C), 90 days (D), 180 days $(E)$, and 240 days (F) (H\&E, $165 X)$. See the increase in thickening and the formation of utricles and cysts in the dermis.

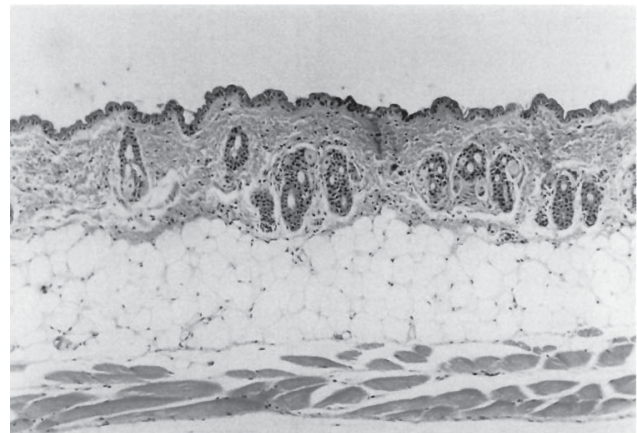

A

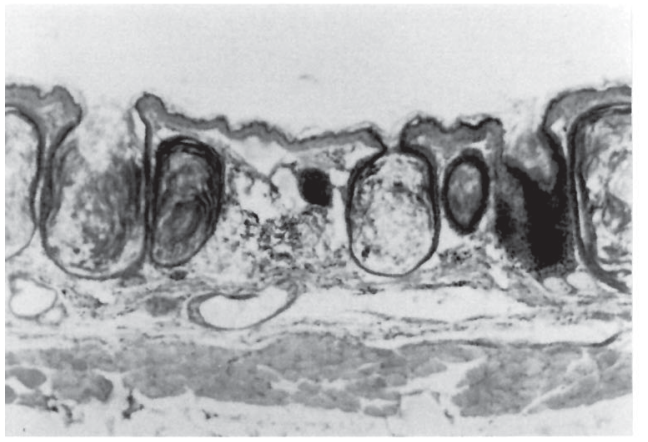

C

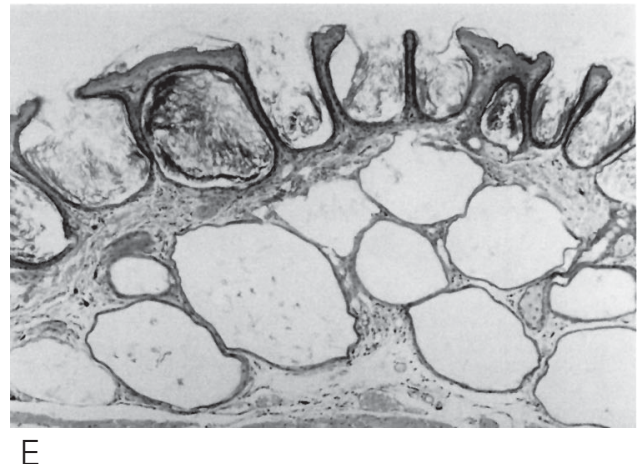

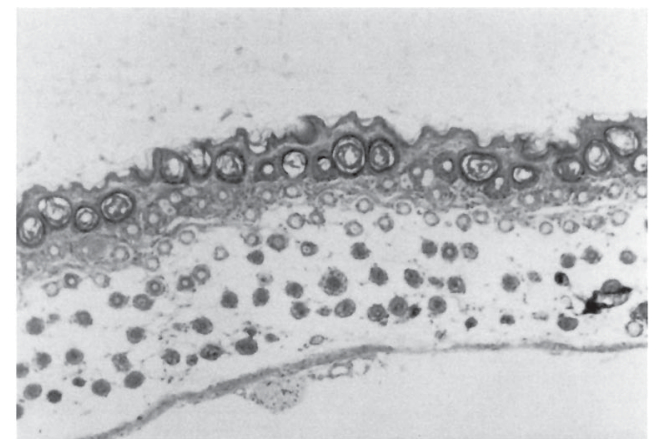

B

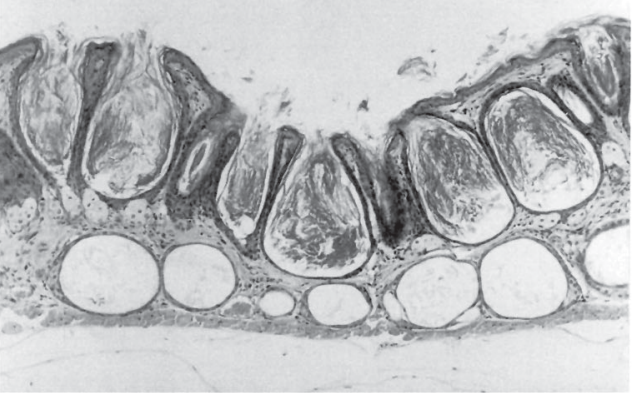

D

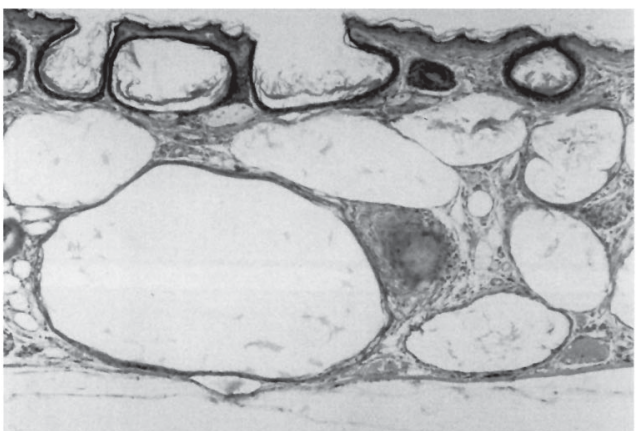

F

Table 3. Thickness of skin structures in male hrUSP and BALB/c mice of different ages.

\begin{tabular}{llccccc}
\hline Skin structure & Genotype & 18 days & 30 days & 90 days & 180 days & 240 days \\
\hline Epidermis & BALB/c & $0.019+0.01$ & $0.012+0.01$ & $0.018+0.01$ & $0.020+0.01$ & $0.014+0.01$ \\
& hrUSP & $0.017+0.01$ & $0.015+0.01$ & $0.016+0.01$ & $0.023+0.01$ & $0.014+0.01$ \\
Dermis & BALB/C & $0.360+0.11$ & $0.468+0.05$ & $0.362+0.04$ & $0.372+0.14$ & $0.244+0.04^{*}$ \\
& hrUSP & $0.277+0.09$ & $0.323+0.04$ & $0.340+0.11$ & $0.405+0.11$ & $0.447+0.06$ \\
Epidermis & BALB/c & $0.379+0.11$ & $0.480+0.05$ & $0.381+0.04$ & $0.392+0.14$ & $0.258+0.05^{*}$ \\
dermis & hrUSP & $0.293+0.089$ & $0.337+0.04$ & $0.356+0.113$ & $0.429+0.11$ & $0.461+0.06$ \\
\hline
\end{tabular}

Data are reported as means $\pm S D$ in $\mathrm{cm}$ for 5 mice of each strain per age group. ${ }^{*} \mathrm{P}<0.05$ compared to hr USP mice (Student $t$-test). 
this time, skin adnexa (sebaceous glands) were only rarely observed.

$h r^{U S P}$ skin at 240 days of age (Figure $1 F$ ). At this time, the dermis was almost completely replaced by utricles and dermal cysts, which were very large, with thin walls, and contained almost no keratin. Dermal connective tissue was scant. The hypodermis and muscle layers were very thin. Epidermis, utricles, dermal cysts and also the sebaceous glands stained positively for the AE1/AE3 antibodies at all times studied.

\section{Skin thickness during growth}

Table 3 shows the skin thickness data for mutant and BALB/c mice. By 240 days of age the dermis of the mutants was significantly thicker than that of BALB/c mice.

\section{Dermal connective tissue}

Collagen. The picrosirius method associated with polarization showed that the dermal collagen fibers were thick and strongly polarized to red or orange-yellow, suggesting the collagen type I pattern. Some thin fibers that polarize to green were seen, representing collagen type III according to Junqueira et al. (4). The amount of dermal collagen fibers varied according to mouse age. In younger animals, collagen fibers were abundant in the dermis, but appeared to decrease from 6 to 8 months of age, mainly because cysts and utricles occupied the dermis.

Reticular fibers. Both mutant and BALB/ c mice presented thin argyrophilic fibers distributed as a meshwork in the dermis around the cysts and the hair follicles.

Elastic fibers. Elastic fibers were detected in the dermis of both mutant and BALB/c mice by the Weigert resorcin-fuchsin method, but not by the Verhoeff method. Thin dark brown elastic fibers were seen close to the dermo-epidermal junction, and thicker fibers were seen deeply in the dermis. Inter- mediate thick fibers were also seen distributed in the dermis. The positivity to Weigert staining and the thickness of the fibers suggested the presence of oxitalanic, elauninic and elastic fibers in the skin of both mutant and $\mathrm{BALB} / \mathrm{c}$ mice. The amount and distribution of these fibers did not vary with the phenotype or age of the mice.

Glycosaminoglycans. Acid glycosaminoglycans, stained blue by the Alcian blue method, were equally seen in the dermis of both mutant and BALB/c mice. Neutral glycosaminoglycans were detected by the PAS method in the basal membranes of the epidermis, sebaceous glands, cysts, and utricles. No difference was seen between mutant and wild-type BALB/c mice.

Fibronectin and laminin. Immunohistochemical staining of fibronectin and laminin was seen in the basal layer of the epidermis, as well as in the cysts and utricles of the mutant mice. No differences were detected in the thickness or distribution of these components between mutant and wild-type $\mathrm{BALB} / \mathrm{c}$ mice.

Mast cells and macrophages. Mast cells were stained by the Gomori method (aldehyde-fuchsin), in the skin of both mutant and wild-type BALB/c mice. These cells were scattered in the dermis, without any preferential distribution. No differences were observed between phenotypes or ages. Macrophages of both mutant and BALB/c mice stained positively with HAM 56 antibodies. No differences were observed in the number or distribution of macrophages between phenotypes or ages.

\section{Discussion}

Hairless and rhino mutations are autosomal recessive allelic mutations that map to chromosome 14 (2). Mutant hr/hr mice develop a syndrome characterized by hair loss after growth of the first coat, development of rudimentary mammary glands and susceptibility to lymphomas. The skin appears 
wrinkled and the nails are grotesquely curved. Rhino mutants have similar but more severe gross lesions similar those of $\mathrm{hr} / \mathrm{hr}$ mice, and rhino mice have skin of normal appearance and hair at birth and lose hair from head to tail from 12 days of age on. Homozygous animals become devoid of all general body hair and fail to develop any new hair throughout life. The skin becomes progressively loose, forming folds, flaps and ridges. The skin surface expands after the filling of abortive hair follicles with cornified debris from the utricles. The utricles become enlarged and are grossly visible as uniform, white, subcutaneous nodules (2).

In the present study, we characterized the ENU-induced $\mathrm{hr}^{\mathrm{USP}}$ mutant (3) in terms of the skin of these mice by histological, histochemical and immunohistochemical methods. Our goal was to study the distribution of the skin components and to determine which of the histopathological alterations of the skin paralleled the clinical alterations observed during growth. Our mutants were indistinguishable from wild-type BALB/c mice at birth since their first hair coat developed normally. However, they started to lose hair after the first hair cycle, becoming completely naked from the age of 16 days like some other hairless mutants (2). As the mice aged, they developed wrinkled skin and long curved nails. Other alterations in these mice were hyperplasia of the lymph nodes and a membranous glomerulonephritis seen in older animals, as described previously (3). Histological examination of the skin showed a thin epidermis formed by a stratified epithelium and a dermis rich in dermal cysts. Our results show that these cysts probably originated from hair follicles, still keeping the sebaceous glands attached to them. Cysts were already present at 18 days and enlarged progressively through life. Growth of the hair follicles turned the skin progressively thicker, so that at 240 days (or 8 months) it was significantly thicker compared to the skin of wild-type BALB/c mice of the same age. This increase in skin thickness can be accounted for by the enlargement of cysts since the epidermis showed no other differences during the period studied when compared to the skin of BALB/c mice.

To study the distribution of skin components, connective tissue, extracellular matrix and cells were selectively stained. The expression of fiber components was studied using the picrosirius, reticulin, Weigert, and Verhoeff histochemical stains, and by immunohistochemical staining for fibronectin and laminin. The staining patterns of the extracellular matrix of mutant mice did not differ qualitatively from those of BALB/c mice. However, it is possible that quantitative differences would have been observed if quantification methods had been applied. The same could be true for the glycosaminoglycan component. Neutral glycosaminoglycans were visualized by PAS staining, while acid glycosaminoglycans were visualized by Alcian blue staining. About the connective tissue cells, mast cells and macrophages were scattered in the dermis, with no difference between mutant and BALB/c mice.

It has been reported that the amount of cellular matrix is reduced with aging, as is also the case for collagen located close to dermal cysts (5). The hairless skin was used as a model to study the modulation of collagen, glycosaminoglycans, and fibronectin following treatment with corticosteroids and retinoids, preventing skin atrophy. The reticular fibers which are present close to the hair follicles in the controls, were seen together with the dermal cysts in the mutant. Changes in the structure and distribution of the dermis components were also observed. There was no defined structural pattern and the distribution of elastic fibers, of the fundamental amorphous substance and of neutral polysaccharides was also altered.

In contrast to other mutants (2), the presence of granulomatous inflammation of the dermis associated with rupture of the follicles was not observed in hr ${ }^{\mathrm{USP}}$ mutants. 
Generalized acanthosis and orthokeratosis of the skin affecting the entire body of the mouse, a characteristic pattern for other mutants, were also seen in our mice.

An interesting finding was that the lesions of hairless skin begin at the end of the first hair cycle when the dermal papilla fails to follow the contracting follicles and becomes isolated in the reticular dermis and hypodermis. The presence of cysts was detected in the skin of 18-day-old mice which had small dermal cysts that grow with aging, filling the whole dermis. The structure and constitution of the dermal cysts of rhino mice were described by Bernerd et al. (6), who found strong similarities to sebaceous glands and outer sheet roots.

While the hairless mutants have been largely used as models to test products that reduce skin aging, damage by UVB rays, and changes in skin due to acid treatment, no description of the skin of these mice appears to have been reported. We have shown here that all the normal skin components are present in hairless skin although their distribution is altered by the presence of dermal cysts.

\section{References}

1. Sundberg JP \& King LE (2000). Skin and its appendages: normal anatomy and pathology of spontaneous, transgenic and target mouse mutations. In: Ward JM, Mahler JF, Maronpot RR \& Sundberg JP (Editors), Pathology of Genetically Engineered Mice. lowa State University Press, Ames, 10, USA.

2. Sundberg JP (1994). The hairless (hr) and rhino (hrrh) mutations, chromosome 14. In: Sundberg JP (Editor), Handbook of Mouse Mutations with Skin and Hair Abnormalities: Animal Models and Biomedical Tools. CRC Press, Boca Raton, FL, USA.

3. Massironi SMG, Dagli MLZ, D'Império-Lima MR, Alvarez JM \& Kipnis TL (1994). A new mutant hairless mouse with lymph node hyperplasia and late onset of autoimmune pathology. Brazilian Journal of Medical and Biological Research, 27: 2401-2405.

4. Junqueira LCU, Bignolas G \& Brentani RR (1979). Differential staining plus polarization microscopy: a specific method for collagen detection in tissue sections. Histochemical Journal, 11: 447-455.

5. Schwarz E, Mezick JA, Gendimenico GJ \& Kligman LH (1994). In vivo prevention of corticosteroid-induced skin atrophy by tretinoin in the hairless mouse is accompanied by modulation of collagen, glycosaminoglycans, and fibronectin. Journal of Investigative Der- matology, 102: 241-246

6. Bernerd F, Schwiezer J \& Dermarchez M (1996). Dermal cysts of the rhino mouse develop into unopened sebaceous glands. Archives of Dermatological Research, 288: 586-595.

7. Gordon H \& Sweets HH (1936). A simple method for the silver impregnation of reticulum. American Journal of Clinical Pathology 12: $545-552$.

8. Verhöeff FH (1908). Some new staining methods of wide applicability, including a rapid differential stain for elastic tissue. Journal of the American Medical Association, 50: 876-877.

9. Weigert C (1989). Über eine Methode zur Färbung elastischer Fasern. Zentrablatt für Allgemeine Pathologie und Pathologische Anatomie, 9: 289-292.

10. Lison L (1960). Histochimie et Cytochimie Animales. 3rd edn Gauthier-Villars, Paris, France.

11. Michalany J (1980). Técnica Histológica em Anatomia Patológica. E.P.U., São Paulo, SP, Brazil.

12. Gomori G (1950). Aldehyde-fuchsin, a new stain for elastic tissue. American Journal of Clinical Pathology, 20: 665-666. 